\title{
Evaluating Investments in Typhoid Vaccines in Two Slums in Kolkata, India
}

\author{
Joseph Cook', Dipika Sur², John Clemens ${ }^{3}$, and Dale Whittington ${ }^{4,5}$ \\ 'Evans School of Public Affairs, University of Washington, Seattle, USA, ${ }^{2}$ National Institute of Cholera and Enteric Diseases, \\ Kolkata, India, ${ }^{3}$ International Vaccine Institute, Seoul, Korea, and ${ }^{4}$ Department of Environmental Sciences and Engineering, \\ University of North Carolina, Chapel Hill, USA, and ${ }^{5}$ Manchester Business School, UK
}

\begin{abstract}
New-generation vaccines against typhoid fever have the potential to reduce the burden of disease in areas where the disease is endemic. The case for public expenditure on typhoid Vi polysaccharide vaccines for two low-income, high-incidence slums (Narkeldanga and Tiljala) in Kolkata, India, was examined. Three measures of the economic benefits of the vaccines were used: private and public cost-of-illness (COI) avoided; avoided COI plus mortality risk-reduction benefits; and willingness-to-pay (WTP) derived from stated preference (contingent valuation) studies conducted in Tiljala in 2004. Benefits and costs were examined from a social perspective. The study represents a unique opportunity to evaluate typhoid-vaccine programmes using a wealth of new site-specific epidemiological and economic data. Three typhoid-vaccination strategies (targeting only enrolled school children, targeting all children, and targeting adults and children) would most likely pass a social cost-benefit test, unless benefits are restricted to include only avoided COI. All three strategies would be considered 'very cost-effective' using the standard comparisons of cost per disability-adjusted life-year avoided with per-capita gross domestic product. However, at an average total cost per immunized person of US\$ 1.1, a typhoid-vaccination programme would absorb a sixth of existing public-sector spending on health (on a per-capita basis) in India. Because there appears to be significant private economic demand for typhoid vaccines, the Government could design a financially-sustainable programme with user-fees. The results show that a programme where adults pay a higher fee to subsidize vaccines for children (who have higher incidence) would avoid more cases than a uniform user-fee and still achieve revenue-neutrality.
\end{abstract}

Key words: Costs and cost analysis; Cost-benefit analysis; Evaluation studies; Slums; Typhoid; Typhoid vaccine; India

\section{INTRODUCTION}

Many new-generation vaccines against important 'neglected' diseases are in various stages of the pipeline of discovery, testing, and large-scale manufacturing. Vaccines against many diseases, e.g. malaria, HIV, and shigellosis, are still under development while other new vaccines, e.g. rotavirus, Hib conjugate, and pneumococcal conjugate vaccines, have been licensed but have yet to be widely incorporated into national immunization programmes. Mod-

Correspondence and reprint requests should be addressed to:

Dr. Joseph Cook

Evans School of Public Affairs

University of Washington

Box 353055

Seattle, WA 98195-3055

USA

Email: jhcook@u.washington.edu

Fax: 206-685-9044 ern vaccines have also been developed for diseases against which first-generation vaccines existed, e.g. cholera and typhoid, but which had either poor efficacy in preventing the diseases, short periods of protection, and/or unacceptable levels of sideeffects. These new-generation vaccines have the potential to produce large reductions in the burden of diseases among the poorest sub-populations worldwide. Vaccination is also a powerful tool for preserving the efficacy of existing pharmaceutical treatments in the face of growing microbial resistance, i.e. to antibiotics, artemisinin for malaria, etc.

In evaluating investments in a new or improved vaccine, we focus on three related economic questions. First, would a programme that provided vaccines at no charge to users pass a social cost-benefit test? A second related question is whether the vaccine is a wise use of scarce public-sector health resources. An investment may pass a social cost-bene- 
fit test and still not be a wise use of public resources if the public-sector budget is constrained, and there are other, even better investments. Finally, if a vaccine passes these thresholds, how can it be financed in practice? This last question is perhaps the more pressing in vaccine policy in the poorest countries. Policy analysts have typically evaluated the cost impact of introducing a single new vaccine into a country's immunization schedule (see Ref. 1 and 2 for two recent examples) but have paid less attention to the cumulative financial impact of adding all of these new vaccines simultaneously.

User-fees in the healthcare sector are controversial, particularly for immunizations. Consideration of user-fees raises difficult issues of how to protect the poor, how to avoid corruption and theft when money changes hands, how to incorporate potential herd-protection effects in vaccine pricing (3), and whether the administrative costs of levying fees outweigh their financial benefits. A financially-sustainable programme may not be feasible where demand for the vaccine is low. Vaccination programmes without user-fees may be possible for these new vaccines if public-sector health spending increases substantially, and/or if donors show expanded and sustained support for fully subsidizing mass vaccinations rather than for $\mathrm{R} \& \mathrm{D}$ and demonstration projects. Otherwise, many developing countries will face a difficult choice. They can either continue with policies that effectively ensure that new vaccines are unavailable to anyone, or promote vaccination strategies that incorporate user-fees.

We report here on an economic analysis of vaccination against typhoid fever using the Vi polysaccharide vaccine in two impoverished slums in Kolkata, India. Typhoid fever, caused by the bacterium Salmonella enterica serovar Typhi, is transmitted through contaminated food or water and characterized by high fever, chills, nausea, headache, and malaise, sometimes with delirium (4). The global burden of typhoid fever was estimated at 21 million cases and more than 200,000 deaths in 2000, although true incidence is most likely higher because of inadequate surveillance and under-reporting. South and Southeast Asia is believed to have the highest incidence rates (5). The Vi polysaccharide vaccine, given as an injection, requires only one dose (4). The best available estimates indicate that the Vi vaccine is safe and $65 \%$ protective, with protection lasting at least three years (6-8). This vaccine is internationally licensed for children aged two years and above $(9,10)$.
There are relatively few published economic evaluations of typhoid-vaccination programmes. Papadimitropoulos et al. examined the cost-effectiveness of two types (Ty21a and Vi polysaccharide) of typhoid vaccines for travellers (11). They found that neither vaccine was cost-effective unless travellers were visiting areas with very high incidence rates (200 cases per million travellers) or expected to be in very close personal contact with local inhabitants. Under a range of vaccine-cost estimates, however, Poulos et al. found that immunizing preschool children against typhoid fever in a high-incidence urban slum in Delhi would actually be cost-saving to the public sector (12). They also found that immunizing other age-groups would likely pass a social cost-benefit test when privately-borne cost-ofillness were counted as benefits of vaccination.

This previous work on the economic attractiveness of typhoid-vaccination programmes can be greatly enriched using the results of recent research from the Diseases of the Most Impoverished (DOMI) Programme. The DOMI programme, administered by the International Vaccine Institute in South Korea and funded by the Bill \& Melinda Gates Foundation, involved a number of parallel activities, including epidemiological studies, economic studies, and investigation of the feasibility of vaccinetechnology transfer. Using a contingent valuation approach (discussed in more detail below) in Hue, Viet Nam, Canh et al. found that the private benefits that would accrue to the average household in Hue (with 5.6 household members), if all household members received a Vi vaccine, ranged from US\$ 21 to US\$ 27 (13). They found that a vaccination programme without user-fees would most likely pass a social cost-benefit test but that there was also significant potential for the programme to be self-financing through user-fees. Cook et al. used DOMI data from four sites in Asia (North Jakarta, Indonesia; Hue, Viet Nam; Karachi, Pakistan; and the same two Kolkata slums examined in this paper) to examine the cost-effectiveness of typhoid $\mathrm{Vi}$ vaccination programmes (14). They found that programmes targeting either children or both children and adults were 'very cost-effective' in Karachi, Kolkata, and North Jakarta but not in Hue.

\section{MATERIALS AND METHODS}

\section{Analysis approach}

Although we include results from this parallel costeffectiveness analysis (14), we focus here on a social cost-benefit criterion that is less commonly used in the economic evaluation of vaccines. Do the total 
economic benefits of a publicly-provided typhoidvaccination programme or strategy (i.e. without user-charges) exceed the total economic costs? (For more background on social benefit-cost analysis, see Ref.15 or 16).

We examined three different types of vaccination strategies. All three types of strategies are campaigns; we assume that the vaccinations will not be folded into a routine infant-vaccination programme, such as Expanded Programme on Immunization (EPI) because (a) like other polysaccharide vaccines, the $\mathrm{Vi}$ vaccine is not licensed for children aged less than two years, and (b) the incidence is higher in older children. The first school-based strategy (we will denote it as strategy ' $S$ ') would target only children aged 5-14 years actually attending school. The second school-based strategy (strategy ' $C$ ') would target all children, less than 15 years, who are old enough to receive the vaccine safely ( $>2$ years). We assume that parents or caretakers would bring unenrolled children to the school for vaccination. The third type of strategy would target adults as well as all eligible children and would require a community-based vaccination campaign (strategy ' $\mathrm{CA}^{\prime}$ for children and adults). For all three vaccination strategies, we assume a one-period model, i.e. we estimate the costs of immunizing the target population in year 1 and compare these costs with the effects on the burden of disease over the duration of the vaccine's effectiveness (3 years).

We use three definitions of economic benefits. The first definition includes only the privately- and publicly-borne cost-of-illness (COI) avoided as a result of the vaccination strategy. This is the most commonly-used measure in social benefit-cost analyses of vaccination programmes. The second definition adds the value of reducing mortality risk (the chance of dying from typhoid fever) through a value-of-statistical-life (VSL) calculation. By measuring or observing how people trade money for changes in their risks of dying (for example, by buying bicycle helmets or demanding higher wages for risky jobs), one can calculate the average willingness-to-pay (WTP) of society to avoid risks that will result on average in one less death in a population (a 'statistical' life). VSL calculations do not attempt to place an economic value on the life of any particular person. Although the risk of dying from typhoid fever may be low in Kolkata, these benefits may be quite important to people at risk of getting typhoid fever. In a contingent valuation survey of cholera vaccines in Beira, Mozambique, $55 \%$ of respondents said that the most important benefit of the vaccine was reducing their risk of dying (17).

The third definition of economic benefits is based on the WTP observed in studies using the contingent valuation methodology in one of the two neighbourhoods we evaluated. 'Willingness-to-pay' refers to the total economic value that a person places on a good or service, or the area under the private demand curve less expenditure on the goods or service. For a vaccine with no user-charge, WTP represents the total economic benefits that accrue to the person from receiving the free vaccine. These WTP estimates should be the most comprehensive measure of the economic benefits of vaccination, assuming that respondents were thinking about avoiding potential typhoid-treatment costs, lowering the risk of dying for themselves and their household members, and other benefits which are more difficult to quantify in the first two definitions (pain and suffering, fear, risk aversion, etc.). Since one would not expect individuals' private valuations to include publicly-borne treatment cost, we add this to these stated preference estimates of WTP for our third definition of economic benefits.

The economic cost of a typhoid-vaccination strategy is composed of three main components: (a) the cost of acquiring vaccines from the manufacturer, (b) the cost of delivering and administering the vaccine to the target population, and (c) the time and pecuniary costs incurred by household members to travel to the vaccination outpost and to wait to receive the vaccine. For each of the three economic bene-fit measures, we subtract the total economic costs to calculate net benefits. We refer to these measures of net benefits as 'avoided COI net benefits', 'VSL+avoided COI net benefits', and 'WTP+avoided public COI net benefits'. Table 1 summarizes the three measures [The online appendix (http://www.icddrb.org/jhpn) provides more details on how they are calculated].

We examine the sensitivity of our results in two ways. First, we find the value of the most important parameters which would produce exactly zero net benefits, i.e. the programme or strategy would 'breakeven'. Second, we allow the parameters to vary simultaneously in a Monte Carlo framework. We used Crystal Ball, a plug-in from Oracle for MS Excel, to run the simulations. The results presented used 10,000 draws from triangular parameter distributions for all variables, with low and high ends of the distribution set to the uncertainty ranges and the peak of the triangle set to the mean value. 


\begin{tabular}{|lc|}
\hline \multicolumn{2}{|l|}{ Table 1. Definitions of social net benefit measures } \\
\hline Name & Definition \\
\hline Avoided COI net benefits & {$[$ Cases avoided * (private+public COI per case) $]$} \\
& - (acquisition costs+delivery costs+travel and time costs) \\
VSL+avoided COI net benefits & {$[$ Cases avoided * (private+public COI per case) $]$} \\
& + (deaths avoided * value of statistical life) \\
& - (acquisition costs+delivery costs+travel and time costs) \\
WTP+avoided public COI net & (Willingness-to-pay per person for vaccine) \\
benefits & + (cases avoided * public COI per case) \\
& $-($ acquisition costs+delivery costs+travel and time costs) \\
\hline COI=Cost-of-illness; VSL=Value-of-statistical-life; WTP=Willingness-to-pay
\end{tabular}

\section{Study site}

Kolkata (formerly Calcutta) is the third largest city in India, with a population of 4.6 million in the city proper and approximately 13 million in the greater metropolitan area (18). Of the 4.6 million people, approximately 1.5 million currently reside in slums (both officially recognized and unofficial) (18). Our focus was on two Kolkata slums-Tiljala and Narkeldanga - where we carried out economic and epidemiological field studies in 2004. With a combined population of 185,000 living in approximately five sq km, Tiljala and Narkeldanga are very densely-crowded areas. Both are highly impoverished: per-capita daily income is approximately US\$ 0.40 . Over $90 \%$ of the sample in Tiljala lived on less than US\$ 1 per capita per day, and no one had a per-capita income over US\$ 3 per day.

\section{Parameters \\ Epidemiology}

The baseline epidemiology comes from an 11month passive surveillance study of typhoid cases in Narkeldanga conducted in advance of a typhoid vaccine-demonstration project (19). Ochiai et al. observed 122 blood culture-confirmed typhoid cases in 12 months in the census population of 57,000 , yielding typhoid incidence rates of 3.4 , 4.9 , and 1.2 cases per 1,000 population for young children aged 2-4 years, school children aged 5-15 years, and adults (aged 16+ years) respectively (Table 2). Since blood-culture tests for typhoid fever are only around 50\% sensitive (5), we followed Crump et al. (5) and Ochiai et al. (19) and doubled these observed incidence rates.

We used $65 \%$ as the base case for vaccine efficacy, ranging from $55 \%$ to $75 \%$ in the uncertainty analysis $(9,10)$. Although indirect (herd) protection may reduce cases even further, we included only direct protection in our analysis because empirical evi- dence of herd protection from typhoid vaccination was not available in the published literature at the time of writing (these became available as this article was in press, see Ref. 20). We assumed that the duration of the vaccine's protection is three years $(9,10)$.

According to the World Health Organization (WHO), the case-fatality rate (CFR) for typhoid cases treated with antibiotics is about 1\% (21). The CFR without treatment can range from $4 \%$ to $10 \%$ (21). The CFR in a January 2005 outbreak in Congo was $0.5 \%$ (214 deaths in 42,564 cases), although it is unclear what level of treatment these patients received (22). Crump et al. used 1\% based on "conservative estimates from hospital-based typhoid fever studies, mortality data from countries with reliable national typhoid fever surveillance systems that employ blood culture confirmation of cases, and expert opinion" (5). Parry et al. also cited 1\% as a good estimate (4). Accordingly, we used a CFR of $1 \%$ as our base case estimate, with lower and upper bounds of $0.5-3 \%$ for uncertainty analysis.

Parry et al. reported a range of 'mean fever clearance times' with different antibiotics from four to seven days, increasing to a mean of nine days in 'clinical failures' or cases where antimicrobials were not initially successful (4). Treatment times can increase to 21 days if third-line antibiotics, e.g. cephalosporins, are necessary (4). We assumed that the average typhoid case lasts for one week, with lower and upper bounds of four days and three weeks respectively.

In the cost-effectiveness calculations, we use a mean disability-adjusted life-year (DALY) weight of 0.27 , which lies within a range of weights for somewhat similar diseases (malaria, Japanese encephalitis, dengue, and upper respiratory infections) (23). The lower and upper bounds are those for dengue fever (0.08) and neurological sequelae of malaria (0.47). 


\begin{tabular}{|c|c|c|c|}
\hline Site characteristics & Base case value & $\begin{array}{c}\text { Uncertainty } \\
\text { range }\end{array}$ & Source \\
\hline Total population (Tiljala and Narkeldanga) & 185,000 & & 24 \\
\hline Children aged $<1$ year & 2 & & 24 \\
\hline Children aged 1-4 year(s) (\% of population) & 7 & & 24 \\
\hline Children aged 5-14 years (\% of population) & 20 & & 24 \\
\hline Adults aged $15+$ years (\% of population) & 72 & & 24 \\
\hline \multicolumn{4}{|l|}{ Epidemiology } \\
\hline Incidence per 1,000: children aged 0-1.9 year(s) & 0.9 & $0.16-5.0$ & 19 \\
\hline Incidence per 1,000: children aged 2-4.9 years & 3.4 & $1.9-6.3$ & 19 \\
\hline Incidence per 1,000 : children aged 5-14.9 years & 4.9 & $4.0-6.7$ & 19 \\
\hline Incidence per 1,000: adults aged $15+$ years & 1.2 & $0.94-1.6$ & 19 \\
\hline Blood culture sensitivity multiplier & 2 & & 19 \\
\hline Case-fatality rate $(\%)$ & 1.0 & $0.5-3$ & $4,5,21$ \\
\hline DALY weight & 0.27 & $0.08-0.47$ & See text, 23 \\
\hline Average duration (days) of case & 7 & 4-21 & 4 \\
\hline \multicolumn{4}{|l|}{ Vaccine characteristics and costs } \\
\hline Effectiveness (\%) & 65 & $55-75$ & 9,10 \\
\hline Duration (years) & 3 & & 9,10 \\
\hline Manufacturing cost (US\$) per dose & 0.57 & $0.4-0.8$ & Lauria and Stewart \\
\hline Delivery cost (US\$) per dose & 0.50 & $0.3-2.5$ & Lauria and Stewart \\
\hline Travel/time cost (US\$) per dose & 0.06 & & Author's calculation \\
\hline \multicolumn{4}{|l|}{ Cost-of-illness (US\$) } \\
\hline Private COI children aged $<15$ years & 11.7 & $6-18$ & Poulos et al. \\
\hline Private COI adults aged >15 years & 11.7 & $6-18$ & Poulos et al. \\
\hline Public COI children aged $<15$ years & 4.3 & $2-6$ & Poulos et al. \\
\hline Public COI adults aged $>15$ years & 4.3 & $2-6$ & Poulos et al. \\
\hline \multicolumn{4}{|l|}{ Demand/benefit measures } \\
\hline$\%$ who would take if free: children aged 2-4 years & 73 & $58-88$ & 25 \\
\hline$\%$ who would take if free: children aged 5-14 years & 69 & $55-83$ & 25 \\
\hline$\%$ who would take if free: adults aged $15+$ years & 62 & $50-74$ & 25 \\
\hline Slope of demand curve: children aged 2-4 years & -0.14 & -0.11 to -0.17 & 25 \\
\hline Slope of demand curve: children aged 5-14 years & -0.27 & -0.21 to -0.32 & 25 \\
\hline Slope of demand curve: children aged 15+ years & -0.28 & -0.22 to -0.34 & 25 \\
\hline Per vaccine WTP (US\$): children aged 2-4 years & 5.2 & $4.2-6.3$ & 25 \\
\hline Per vaccine WTP (US\$): children aged 5-14 years & 2.6 & $2.1-3.1$ & 25 \\
\hline Per vaccine WTP (US\$): adults aged 15+ years & 2.2 & $1.8-2.7$ & 25 \\
\hline \multicolumn{4}{|l|}{ Other parameters } \\
\hline$\%$ of population who hear of programme & 80 & & 26,27 \\
\hline School enrollment rate (\%) & 69 & & 28 \\
\hline Discount rate $(\%)$ & 3 & & 29 \\
\hline VSL (US\$) young children (aged <5 years) & 50,000 & $25 \mathrm{k}-75 \mathrm{k}$ & 30, Maskery et al. \\
\hline VSL (US\$) school-age children (aged 5-14 years) & 50,000 & $25 \mathrm{k}-75 \mathrm{k}$ & 30, Maskery et al. \\
\hline VSL (US\$) adults (aged 15+ years) & 50,000 & $25 \mathrm{k}-75 \mathrm{k}$ & 30, Maskery et al. \\
\hline
\end{tabular}




\section{Cost-of-illness}

Culture-positive patients from the surveillance were invited to participate in a private COI study [Poulos C. et al. Cost of illness due to typhoid fever in five Asian countries. 2008. (Unpublished working paper)]. Interviewers visited patients at home 7, 14, and 90 days after the onset of illness. For child cases, parents or caretakers were interviewed. A standardized questionnaire measured both direct costs (outof-pocket expenditure on fees, medicines, tests, transportation, etc.) and indirect costs (lost wages and monetized productivity losses, including those for patients, caregivers and their substitutes). The authors found that the mean private COI (direct and indirect) was US\$ 11.7 per case.

Data on publicly-borne COI are based on a microcosting (i.e. bottom-up) study of treating 16 hospitalized and 67 outpatient cases at two public hospitals in Kolkata [Poulos C et al. Cost of illness due to typhoid fever in five Asian countries. 2008. (Unpublished working paper)]. The public treatment costs (provider treatment costs minus patients' payments) for hospitalized and non-hospitalized cases were, respectively, US\$ 100 and US\$ 2 in Kolkata. Hospitalization rates for adult and child cases were $2 \%$ and $1 \%$ respectively. We use an average public COI, weighed by hospitalization rate, of US\$ 4.3 per case. For both public and private COI, we use values that are $50 \%$ lower or higher than the base case estimate for the sensitivity analysis.

\section{Willingness-to-pay}

The estimates of private demand came from a contingent valuation study carried out in Tiljala in 2004 (25). These household surveys began with questions to respondents about vaccination and typhoid fever. Respondents were then presented with a description of a hypothetical typhoid vaccine that had the characteristics most similar to the real typhoid Vi vaccine (65\% effective for three years). Respondents were told in 2004 that the vaccine would be $70 \%$ effective. New research appearing since that fieldwork has revised the estimate downwards somewhat, to $65 \%$. We used $65 \%$ in calculating programme effects. The interviewer then asked respondents whether they would purchase a vaccine for themselves and for other household members if the price were one of four randomly preassigned prices. The median WTP per person was US\$ 5.2, \$2.6, and \$ 2.2 (in 2007) for young children, school-age children, and adults respectively (More details on the private demand studies and the demand functions used in our analysis are available in the online appendix and in Ref. 25).

\section{Vaccine costs}

None of the three cost components-acquisition costs, delivery costs, and travel/time costs-is known with certainty; they depend on a number of factors for which there is little information in the published literature on vaccine cost. We relied on data collected on vaccination costs during the Vi demonstration projects in the DOMI study sites and a recent review and analysis of this literature by Lauria and Stewart [Lauria D and Stewart J. Vaccination costs. 2007. UNC Department of Environmental Sciences and Engineering (Unpublished manuscript)]. We assumed that costs could be captured in a constant marginal cost measure (a common assumption in the literature on vaccine evaluation), rather than attempt to estimate fixed and variable costs. We assumed that the total marginal economic cost of providing a typhoid vaccine was US\$ 1.11 per dose (in 2007 \$), comprising: (a) a cost to acquire the vaccine (including shipping and wastage) of US\$ 0.57 per dose, (b) a cost to deliver the vaccine of US\$ 0.5 per dose, and (c) a travel/ time cost to recipients of US\$ 0.06 per dose.

\section{Other parameters}

We used the most recent data for India from the United Nations Educational, Scientific and Cultural Organization (28) on the net enrollment rate (Table 2), or the percentage of school-age children who are actually attending school, to calculate the total number of school-age children who might be vaccinated in the first strategy (strategy ' $S$ '). Since the age-group (5-15 years) spans both primary and secondary schools, we used the average of the rates of enrollment in primary and secondary schools in the model.

Estimates of VSLs are now available for a number of less-developed countries. We used a VSL of US\$ 50,000 extrapolated primarily from two recent studies in Delhi, India (30) and Matlab, Bangladesh (Maskery B et al. An estimate of the economic value parents in rural Bangladesh place on ex ante risk reductions for their children. 2008. Presented at 16th Annual Conference of the European Association of Environmental and Resource Economists). More details are available in the online appendix at http://www.icddrb.org/jhpn. Since the VSL estimates are controversial, we also examined the sensitivity of our results to a range of estimates (again, 50\% lower and higher). 


\section{RESULTS}

\section{Base case analysis}

In the absence of any $\mathrm{Vi}$ vaccination strategy, we would expect 2,250 typhoid cases to occur among the population of 185,000 (1,300 cases among children aged less than 15 years, and 950 cases among adults) over three years (Table 3 ). With a CFR of $1 \%$, we would anticipate 23 deaths over three years due to typhoid fever. We expect that a communitybased strategy that charged no user-fees (strategy $\mathrm{C}^{\circ} \mathrm{A}^{\circ}$ in Table 3 , where the superscript numbers denote a user-fee of zero) would vaccinate approximately half of the population. This is because we assumed that only $80 \%$ of the population heard about the programme through an information and public-health advocacy campaign and because not everyone who heard of the campaign will choose to be vaccinated (based on our private demand estimates from the contingent valuation survey). This would reduce the burden of disease by $35 \%$ (recall also that the $\mathrm{Vi}$ vaccine is about $65 \%$ effective). Targeting only children in the two slums (strategy $\mathrm{C}^{0}$ ) would require fewer financial resources than including adults (US\$27,149 vs US\$ 95,981). The savings to the public-health sector from not treating typhoid cases (US\$ 1,871 for $\mathrm{C}^{\circ}$ and US\$ 3,113 for $\mathrm{C}^{\circ} \mathrm{A}^{\circ}$ ) is much less than the costs of either vaccination strategy.

Using the most common definition of economic benefits in the literature on health policy that in-

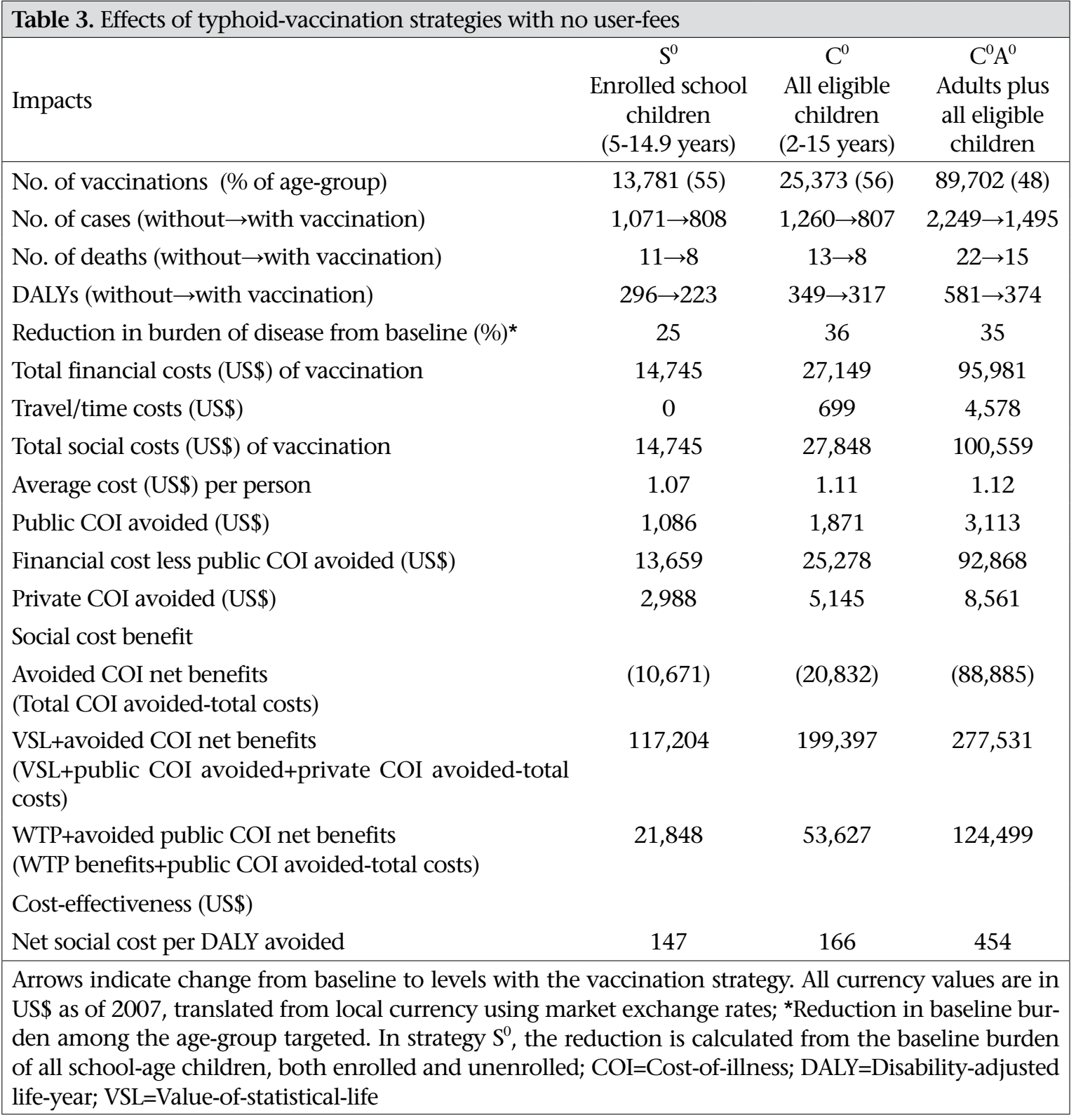


cludes only avoided treatment costs (avoided COI net benefits), none of the three strategies would pass a social cost-benefit test (Table 3, row 13). If we incorporate the benefits of mortality-risk reduction (through a VSL calculation) or take respondents' stated WTP as the measure of benefits, all three strategies would, however, pass (row 14 and 15). Using a cost-effectiveness (CE) approach, the three strategies have net social costs per DALY avoided of US\$ 147, US\$ 166, and US\$ 454 respectively (Table 3 and Ref. 14). All three would be considered 'very cost-effective': the ratios are less than per-capita gross domestic product (GDP, US\$ 871 in India in 2007).

\section{Sensitivity analysis}

We first examined parameters individually to find the 'break-even' value that equates economic benefits and costs. Recall that, using the avoided COI net benefits measure, none of the strategies produced net benefits. To break even using the COI net benefit measure, incidence or total COI would need to be 4-8 times higher than observed (Table 4). Alternatively, the vaccine would have to have a much lower average cost than we assumed to break even using the avoided COI net benefit measure. For the community-based strategy $\left(\mathrm{C}^{0} \mathrm{~A}^{0}\right)$ to pass, the Government would need to be confident that it could purchase, store, and deliver the vaccine for less than US\$ 0.08 (an unrealistically low cost). None of the strategies would pass a social cost-benefit test even if the typhoid Vi vaccines were 100\% effective.

All three strategies without user-fees passed a social cost-benefit test using the VSL+COI net benefit measure. If the parameters for incidence were $11-27 \%$ of their base case values (Table 4), the strategies would still pass. For example, the strategy $\mathrm{C}^{0}$ targeting all children would still pass if the incidence rates among young children and school children were 0.41 and 0.59 cases per 1,000 respectively. Similarly, CFRs could be much lower than $1 \%\left(0.09 \%\right.$ for strategy $\left.\mathrm{C}^{0}\right)$ and still pass. Estimates of the value of a statistical life could also be much lower than our estimate of US\$50,000 and still pass using this measure. Similarly, average vaccine costs could be as high as US\$ 8-9, and the strategies targeting children would still pass. Likewise, since all three strategies produced net benefits using the WTP measure, average vaccine costs could be higher (US\$ 2-3) or average WTP could be lower than we assumed in the base case scenario and still pass a social cost-benefit test.

We next allowed several uncertain parameters to vary simultaneously in a Monte Carlo framework.

\begin{tabular}{|c|c|c|c|}
\hline Parameter & $\begin{array}{c}\mathrm{S}^{0} \\
\text { School-age } \\
\text { children } \\
\text { (5-14.9 years) }\end{array}$ & $\begin{array}{c}\mathrm{C}^{0} \\
\text { All eligible } \\
\text { children } \\
\text { (2-14.9 years) }\end{array}$ & $\begin{array}{c}\mathrm{C}^{0} \mathrm{~A}^{0} \\
\text { Adults plus all } \\
\text { eligible } \\
\text { children }\end{array}$ \\
\hline \multicolumn{4}{|l|}{ Net benefits: avoided COI } \\
\hline $\begin{array}{l}\text { Incidence (per 1,000), or } \\
\text { total (public+private) COI (US\$) }\end{array}$ & $3.6 \mathrm{x}$ & $4.0 \mathrm{x}$ & $8.6 \mathrm{x}$ \\
\hline Total financial vaccine cost (US\$) & 0.30 & 0.25 & 0.08 \\
\hline \multicolumn{4}{|l|}{ Net benefits: VSL+avoided COI } \\
\hline Incidence (per 1,000) & $0.11 \mathrm{x}$ & $0.12 \mathrm{x}$ & $0.27 \mathrm{x}$ \\
\hline Case-fatality rate (\%) & 0.08 & 0.09 & 0.24 \\
\hline Total financial vaccine cost (US\$) & 9.58 & 8.93 & 4.16 \\
\hline VSL (US\$) & 4,172 & 4,730 & 12,129 \\
\hline \multicolumn{4}{|l|}{ Net benefits: WTP+avoided public COI } \\
\hline Total financial vaccine cost (US\$) & 2.66 & 3.18 & 2.46 \\
\hline Per-capita WTP (US\$) & $0.38 \mathrm{x}$ & $0.33 x$ & $0.44 \mathrm{x}$ \\
\hline \multicolumn{4}{|c|}{$\begin{array}{l}\text { Because } \mathrm{C}^{0} \text { and } \mathrm{A}^{0} \text { have multiple age-groups, the break-even scalar is shown. A scalar below } 1 \text { means that } \\
\text { the parameters could decrease and still break even (i.e. } 0.66=66 \% \text { less). A scalar of } 5.6 \mathrm{x} \text { means that the } \\
\text { relevant parameters would need to increase } 560 \% \text { to break even. The total financial vaccine cost includes } \\
\text { acquisition and delivery costs, not travel/time costs } \\
\text { COI=Cost-of-illness; VSL=Value-of-statistical-life; WTP=Willingness-to-pay }\end{array}$} \\
\hline
\end{tabular}




\begin{tabular}{|c|c|c|c|}
\hline Benefit measures & $\begin{array}{c}\mathrm{S}^{0} \\
\text { School-age children } \\
\text { (5-14.9 years) }\end{array}$ & $\begin{array}{c}\mathrm{C}^{0} \\
\text { All eligible children } \\
\text { (2-15 years) }\end{array}$ & $\begin{array}{c}\mathrm{C}^{0} \mathrm{~A}^{0} \\
\text { Adults plus all } \\
\text { eligible children }\end{array}$ \\
\hline \multicolumn{4}{|l|}{ Avoided COI net benefits } \\
\hline Median & $(17,817)$ & $(34,125)$ & $(137,013)$ \\
\hline 95\% confidence interval & $(34,435)-(8,474)$ & $(63,949)-(17,142)$ & $(241,713)-(77,081)$ \\
\hline$\%$ positive & 0 & 0 & 0 \\
\hline \multicolumn{4}{|c|}{ VSL+avoided COI net benefits } \\
\hline Median & 167,068 & 293,450 & 415,462 \\
\hline 95\% confidence interval & $55,513-405,775$ & $118,329-647,427$ & $141,395-835,950$ \\
\hline$\%$ positive & $>99$ & $>99$ & $>99$ \\
\hline \multicolumn{4}{|c|}{ WTP+avoided public COI net benefits } \\
\hline Median & 14,097 & 39,241 & 73,238 \\
\hline 95\% confidence interval & $(2,213)-26,274$ & $9,159-61,049$ & $(29,944)-143,710$ \\
\hline$\%$ positive & 95 & $>99$ & 90 \\
\hline
\end{tabular}

Avoided COI net benefits were negative for all three strategies in all 10,000 model runs (Table 5). All three typhoid-vaccination strategies in Tiljala would certainly fail a social cost-benefit test if the benefits are restricted to avoided treatment costs. However, the model predicts that all three strategies have a high probability of producing positive net benefits using either the 'VSL+avoided COI' or 'WTP+avoided public COI' net benefit measures. The large discrepancy in mean net benefits between these latter two measures was largely driven by the CFR parameter. The VSL+COI estimates were highly sensitive to this parameter, which we assumed could reach as high as $3 \%$. For $\mathrm{C}^{0} \mathrm{~A}^{0}$, for example, if we changed only the CFR from $1 \%$ to $2 \%$ and kept all other parameters at their mean values, the VSL+avoided COI net benefits jumped from US\$ 277,531 to US $\$ 643,947$. Increasing the CFR to $3 \%$ increased the net benefits to US\$ 1.01 million. Monte Carlo simulations on the cost-effectiveness ratios are provided in Cook et al. (14).

\section{DISCUSSION}

\section{Limitations}

There are several caveats to our analysis. First, we did not incorporate indirect (herd) protection. Results of a cluster-randomized trial of the $\mathrm{Vi}$ vaccine in Kolkata indicate that unvaccinated neighbours and children do receive some indirect protection (20). This could significantly improve both our cost-effectiveness and cost-benefit results.
Second, antibiotic resistance to treatment could increase treatment costs. The surveillance study in Kolkata measured resistance to seven antibiotics, including ampicillin, co-trimoxizole also known as TMP-SMZ, and chloramphenocol. Although public costs were, in fact, higher for drug-resistant cases compared to drug-sensitive cases, the difference was not statistically significant [Poulos C et al. Cost of illness due to typhoid fever in five Asian countries. 2008. (Unpublished working paper)], and we do not distinguish between these two types of cases.

Third, because of extensive training and publicawareness campaigns that accompanied the surveillance studies, there was an increased awareness of the disease among both service providers and patients. Along with the establishment of a community-based clinic in the Kolkata study site, this meant that febrile patients most likely sought treatment more often and earlier than they normally would do. This probably resulted in fewer severe complications, such as splenic rupture (In fact, no splenic ruptures were reported during the surveillance period). This would make the public and private COI observed too low. The availability of over-the-counter antibiotics also raises the possibility that some patients may have self-medicated before seeking treatment, again lowering public treatment costs though not privately-borne costs (19).

Fourth, we use a one-period model that only examines costs and benefits over the period that the vac- 
cine would be effective (three years). Vaccination would, of course, have to re-occur every three years to maintain protection in the population.

\section{Implications for policy and financing}

We return to the three key economic policy questions. First, would a programme or strategy that provided Vi vaccines free of charge in Tiljala and Narkeldanga pass a social cost-benefit test? Using a definition that restricts economic benefits to treatment costs avoided, we found that none of the vaccination strategies would pass a social costbenefit test. However, we believe that this avoided COI measure misses important components of economic benefits, such as reducing mortality risk and pain and suffering. Measures that account for these, using either a VSL or a stated preference approach, indicate that all three programmes would produce net economic benefits. These latter two measures, however, are not widely accepted by health policy analysts. Although we found that the cost-effectiveness and cost-benefit (using the latter two definitions) approaches gave similar results in our study site, we would note that the two methodologies may not always give the same ranking for allocation of a limited public-sector budget. This is because household preferences are not well-reflected in cost-effectiveness ratios.

Second, would the vaccination strategy be a wise use of limited public-health resources in India? One approach for using cost-effectiveness results is to compare them against set cut-off points. One commonly-used metric first used by the World Bank (31) compares CE ratios with per-capita GDP. A strategy with a ratio less than three times percapita GDP is 'cost-effective', and one with a ratio less than per-capita GDP is 'very cost-effective'. By these definitions, all three strategies would be considered 'very cost-effective'. Both strategies targeting children have 95\% confidence intervals below US\$ 871 (14), and the strategy targeting adults and children was below US\$ 871 in $85 \%$ of the Monte Carlo simulations.

Cost-effectiveness analysis is more useful, however, when numerous interventions can be directly compared. The Disease Control Priorities Project is a recent attempt which builds on previous global disease-burden studies by compiling a comprehensive list of health interventions for developing countries and reporting the range of cost-effectiveness ratios in the literature $(32,33)$. Health policy-makers may then use this cost-effectiveness information to set priorities among competing health projects.
How do typhoid fever-vaccination strategies in slums in Kolkata fare compared to other interventions? Although all three strategies have attractive cost-effectiveness ratios, several other 'neglected low-cost opportunities' for South Asia have CE ratios that are generally below all three Kolkata Vi strategies, including: expanding the existing EPI coverage [(US\$ 8 per DALY averted; India's most recentlyreported coverage for measles, and DTP3 immunization was 59\% (34)], HIV/AIDS interventions (US\$ 9-126 per DALY), and tuberculosis vaccination and control (US\$ 8-263 per DALY) (33). Typhoid vaccination in slums might still be a good public investment in the longer term, with growing percapita incomes, rising public spending on health, and achievement of higher-priority health goals in all the Indian states (i.e. near-universal EPI access).

Finally, is a financially self-sufficient vaccination programme in these two slums practically possible? According to the most recently-published national health accounts data for India (2001-2002), total health-related spending nationwide was Rs 1,021 per person (35). Using Indian inflation rates and current exchange rates, we estimate that total percapita health expenditure was about US\$ 32 per year in 2007. Of this total, though approximately $77 \%$ is private health spending, one of the highest percentages in the world $(34,36,37)$. On a percapita basis, public-sector spending is only about Rs 207 (US\$ 6.60 in 2007), among the lowest rates of public spending on health in Asia (around 1.1\% of GDP).

The Government of India is in the midst of an initiative (the National Rural Health Mission) to increase public spending on health in rural, 'disadvantaged' states (36). One goal of the programme is to double or triple public spending on health (to $2-3 \%$ of GDP) from 2005 to 2012 . Because of the programme's rural focus, however, large urban areas, such as Kolkata, may not see large increases in public-sector health spending. Furthermore, most public spending on health in India occurs at the state level (35), and we know of no current initiatives in the state of West Bengal to dramatically expand public-sector health financing.

As in most countries, the Government of India has not asked users to share the cost of immunizations; vaccines in the Government's EPI have been provided free of charge. Some non-EPI vaccines, however, are available for sale in the private market (33). One example is the typhoid Vi polysaccharide vaccine, although the private market is very small and most people are unaware of its availability. In 
Kolkata, for example, it is available for purchase in a small number of private physician's offices, and sales are low. The limited demand we observed in 2004 was principally for young people in wealthier families who needed the vaccine for travel abroad or for school enrollment. At a financial cost of about US\$ 1.07 per vaccinated person, any of the typhoidvaccination strategies would absorb approximately one-sixth of the current per-capita public healthrelated spending in India. As a percentage of total health-related spending by the state or national government, however, a strategy of vaccinating people in only a few low-income, high-incidence slums in major Indian cities would not necessarily pose a large financial burden. It would essentially reflect a redistribution of health subsidies from more well-off urban households and poorer rural households to the poorest urban sub-populations. Furthermore, we do not discount the argument that India should increase public spending on health and decrease reliance on private spending. Typhoid Vi vaccination in high-incidence slums would seem to be a worthwhile use of that expanded funding, especially targeting only school-age children who have the highest incidence.

However, the state and federal governments may place a higher priority on implementing other health interventions with the limited, and even expanded, health funding available to them. Vaccines could, of course, be purchased by external donors rather than by the local or national government. Many of these donors, such as GAVI, see their role, however, as providing short- to medium-term leveraging of the existing resources and catalyzing change and innovation rather than simply procuring vaccines over the long term ( $>10$ years). They may also wish to target their assistance to only those programmes with the most favourable costeffectiveness ratios.

If neither government nor donor support can be marshalled for long-term provision of free $\mathrm{Vi} \mathrm{vac}$ cines-or indeed, any of the competing new-generation vaccines-into such slums, the Government may consider subsidizing some portion of the cost of vaccines but ask the vaccinated to contribute a share of the costs. Some observers may have ethical objections to levying user-fees among a poor and perhaps politically-marginalized sub-population, some of whom may be unable to afford the fees. However, if a government (a) decides that user-fees for vaccines are unacceptable, (b) decides that a vaccine is not attractive enough to include in the national (free) vaccination programme, and (c) prevents the private sector from selling the vaccine at marginal cost (which many developing countries do), many more people are denied access to the vaccine, and the poor, politically-marginalized subpopulation will still go unvaccinated.

Figure 1 shows the frontier of possible user-charges

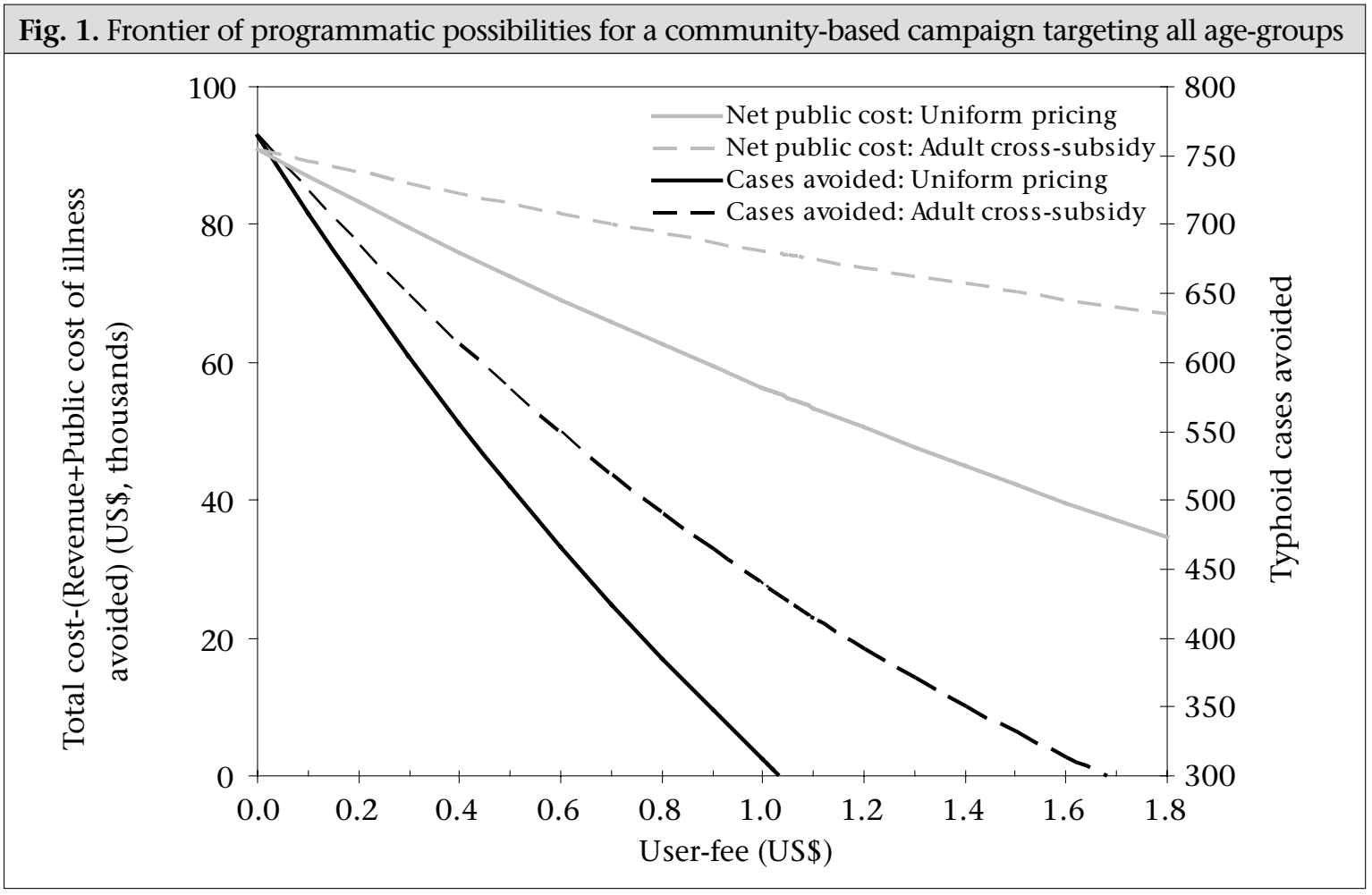


(and implied public subsidies) and their impact on public revenue required (the y-axis on the left) and cases avoided in the two slums (the y-axis on the right). The solid lines show the possibilities for implementing a uniform user-charge, i.e. adults and children pay the same fee. This type of strategy would be revenue-neutral at a fee of US\$ 1.03, just less than the full marginal financial cost of US\$ 1.07 because of public COI savings. It would result in 178 fewer cases than a strategy where vaccines are given free of charge to all age-groups $\left(\mathrm{C}^{0} \mathrm{~A}^{0}\right.$ in Table 3 ). Figure 2 similarly portrays the trade-off between different strategies, with this revenue-neutral strategy labelled $\mathrm{C}^{1.03} \mathrm{~A}^{1.03}$ (again, superscripts denote the user-fees asked of each group). used in our study sites and children were vaccinated free of charge. In our example, for this cross-subsidy scheme to be revenue-neutral, adults would need to be charged a fee of US\$ 1.68 to cross-subsidize free vaccines for children $\left(\mathrm{C}^{0} \mathrm{~A}^{1.68}\right)$. We predict that this would prevent 642 cases (113 fewer than $\mathrm{C}^{0} \mathrm{~A}^{0}$ ) and require no new public-sector financial resources.

It is worth noting three caveats to this financing approach. First, savings from public-sector treatment costs may not be easy to convert into cash to fund vaccination programmes. Second, we have assumed that policy-makers would consider public COI savings in their calculation of revenue-neutrality but

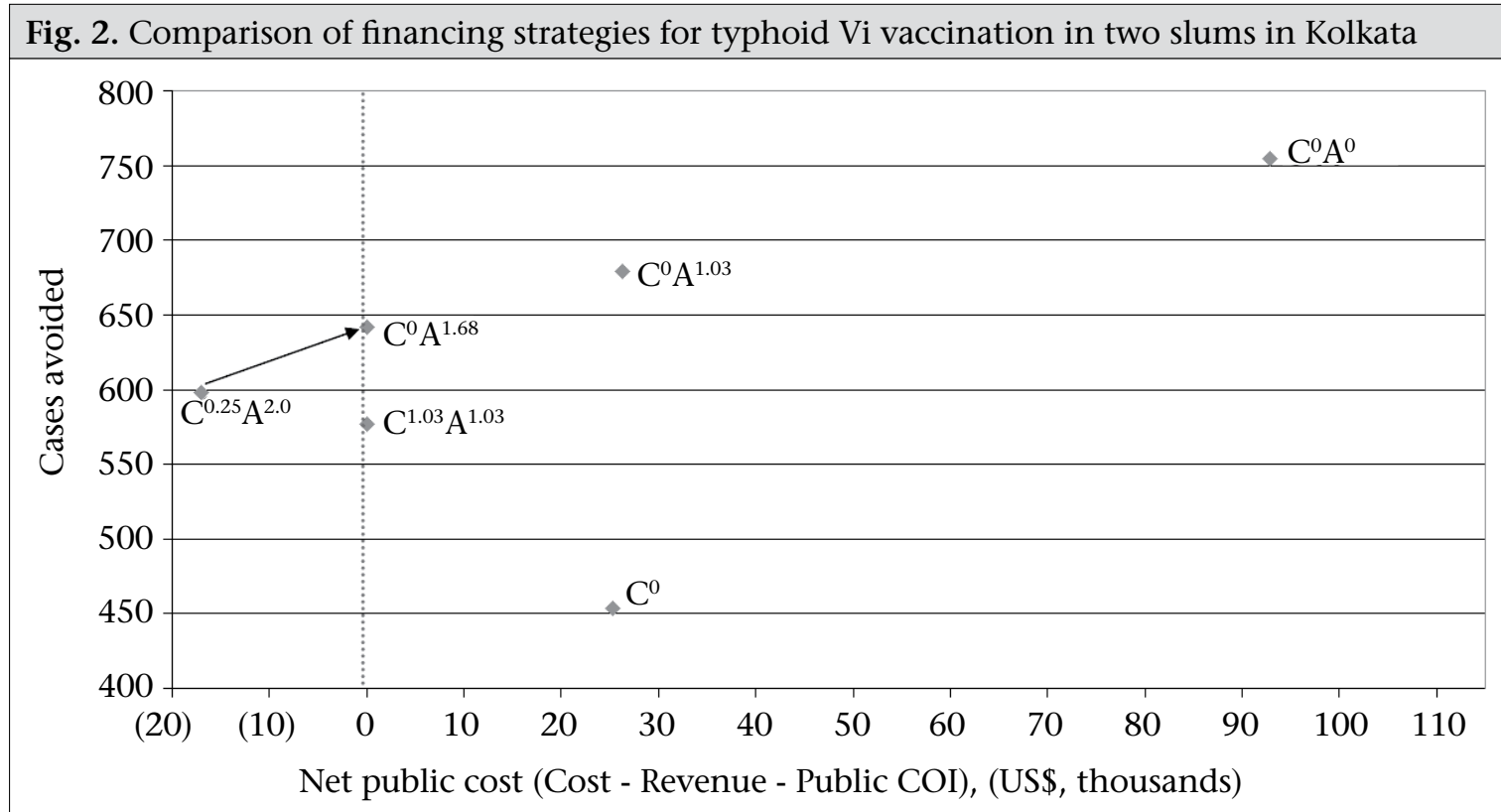

Letter indicates group targeted: ' $\mathrm{C}$ ' is children aged 2-14.9 years; ' $\mathrm{A}$ ' is adults aged over 15 years. Superscript indicates user-fee levied, such that $\mathrm{C}^{0.25} \mathrm{~A}^{2.0}$ indicates a strategy where user-fees are US\$ 0.25 for children and US $\$ 2.0$ for adults. Strategy $\mathrm{C}^{0}$ would target only eligible children; the vaccine would be essentially unavailable to adults; All currency values are in US\$ as of 2007 , translated from local currency using market exchange rates; $\mathrm{COI}=$ Cost-of-illness

A second option would be to provide vaccines free of charge to children but to charge adults the full marginal cost (net of expected public COI savings). This strategy (labelled $\mathrm{C}^{0} \mathrm{~A}^{1.03}$ in Fig. 2) would have a net public cost of US\$26,275 and prevent 679 typhoid cases, only 75 cases fewer than the strategy $\mathrm{C}^{0} \mathrm{~A}^{0}$ without user-fees).

Lauria et al. analyzed a cross-subsidy scheme in which adults were charged prices greater than full marginal cost to subsidize vaccines for children (38). The dashed lines in Figure 1 shows how cases avoided and net public costs change with possible adult user-fees if such a cross-subsidy scheme were they may not. Finally, it is possible that even our most conservative demand estimates from the contingent valuation study are too high, and demand for adults may not materialize. If this were the case, revenues from adults would not be sufficient to cross-subsidize the cost of running the programme for children. The financial risk to the Government of adult demand not materializing is about US\$ 26,000 . To maintain revenue-neutrality, user-fees for adults would then have to be increased (or user-fees for children introduced), both of which might be difficult to implement.

To account for this risk, the Government could ini- 
tially charge adults a fee somewhat larger than the expected revenue-neutral price of US\$ 1.68 (perhaps US\$ 2.00) and charge a small fee for child vaccinations (US\$ 0.25). This strategy (labelled $\mathrm{C}^{0.25} \mathrm{~A}^{2.00}$ in Fig. 2) would, of course, generate excess revenues if our demand estimates are correct (it lies to the left of the revenue-neutral line in Fig. 2). After distributing vaccines with this pricing structure for three years, the Government could assess whether actual demand is similar to our predictions and whether public COI savings are as expected. If so, it could then reduce the price for adults and move the price for children towards zero (depicted with an arrow in Fig. 2). Again, accounting for the effects of indirect herd protection would show even larger reductions in cases and deaths avoided while still maintaining revenue-neutrality.

\section{REFERENCES}

1. Sinha A, Levine O, Knoll MD, Muhib F, Lieu TA. Costeffectiveness of pneumococcal conjugate vaccination in the prevention of child mortality: an international economic analysis. Lancet 2007;369:389-96.

2. Podewils LJ, Antil L, Hummelman E, Bresee J, Parashar UD, Rheingans R. Projected cost-effectiveness of rotavirus vaccination for children in Asia. J Infect Dis 2005;192(Suppl 1):S133-45.

3. Cook J, Jeuland M, Maskery B, Lauria D, Sur D, Clemens $\mathrm{J}$ et al. Re-visiting socially-optimal vaccine subsidies: an empirical application in Kolkata, India. J Policy Anal Manage 2009;28:6-28.

4. Parry CM, Hien TT, Dougan G, White NJ, Farrar JJ. Typhoid fever. N Engl J Med 2002;347:1770-82.

5. Crump JA, Luby SP, Mintz ED. The global burden of typhoid fever. Bull World Health Organ 2004;82:34653.

6. Hessel L, Debois H, Fletcher M, Dumas R. Experience with Salmonella typhi Vi capsular polysaccharide vaccine. Eur J Clin Microbiol Infect Dis 1999;18:60920.

7. Yang HH, Kilgore PE, Yang LH, Park JK, Pan YF, Kim Y et al. An outbreak of typhoid fever, Xing-An county, People's Republic of China, 1999: estimation of the field effectiveness of Vi polysaccharide typhoid vaccine. J Infect Dis 2001;183:1775-80.

8. Yang HH, Wu CG, Xie GZ, Gu QW, Wang BR, Wang LY et al. Efficacy trial of Vi polysaccharide vaccine against typhoid fever in south-western China. Bull World Health Organ 2001;79:625-31.

9. Acosta CJ, Galindo CM, Deen JL, Ochiai RL, Lee HJ, von Seidlein L et al. Vaccines against cholera, typhoid fever and shigellosis for developing countries. Exp Opin Biol Ther 2004;4:1939-51.
10. Acharya IL, Lowe CU, Thapa R, Gurubacharya VL, Shrestha MB, Cadoz M et al. Prevention of typhoid fever in Nepal with the Vi capsular polysaccharide of Salmonella typhi. A preliminary report. N Engl J Med 1987;317:1101-4.

11. Papadimitropoulos V, Vergidis PI, Bliziotis I, Falagas ME. Vaccination against typhoid fever in travellers: a cost-effectiveness approach. Clin Microbiol Infect 2004;10:681-3.

12. Poulos C, Bahl R, Whittington D, Bhan MK, Clemens JD, Acosta CJ. A cost-benefit analysis of typhoid fever immunization programs in an Indian urban slum community. J Health Popul Nutr 2004;22:311-21.

13. Canh DG, Whittington D, Le TK, Utomo N, Nguyen TH, Poulos C, Dang TD et al. Household demand for typhoid fever vaccines in Hue, Vietnam. Health Policy Plan 2006;21:241-55.

14. Cook J, Jeuland M, Whittington D, Poulos C, Clemens J, Sur D et al. The cost-effectiveness of typhoid Vi vaccination programs: calculations for four urban sites in four Asian countries. Vaccine 2008;26:630516.

15. Zerbe RO, Jr., editor. Benefit-cost analysis. 1st ed. Northhampton, MA: Edward Elgar Publishing, 2008. $1,088 \mathrm{p}$.

16. Boardman A, Greenberg DH, Vining A, Weimer DL. Cost-benefit analysis: concepts and practices. 3rd ed. Upper Saddle River, NJ: Prentice-Hall, 2005. 576 p.

17. Lucas M, Jeuland M, Deen J, Lazaro N, MacMahon M, Nyamete A et al. Private demand for cholera vaccines in Beira, Mozambique. Vaccine 2007;25:2599-609.

18. Kundu N. Understanding slums: case studies for the global report on human settlements, 2003. The case of Kolkata, India. London: Development Planning Unit, University College London, 2006. 21 p.

19. Ochiai RL, Acosta CJ, Danovaro-Holliday MC, Baiqing D, Bhattacharya SK, Agtini MD et al. A study of typhoid fever in five Asian countries: disease burden and implications for control. Bull World Health Organ 2008;86:260-8.

20. Sur D, Ochiai RL, Bhattacharya SK, Ganguly NK, Ali M, Manna B et al. A cluster-randomized effectiveness trial of Vi typhoid vaccine in India. N Engl J Med 2009; 361:335-44.

21. World Health Organization. Typhoid fever. 2007. (http://www.who.int/topics/typhoid_fever/en, accessed on 1 March 2008).

22. World Health Organization. Typhoid fever, Democratic Republic of the Congo. Weekly Epidemiol Rec 2005;80:30-31. 
23. Edejer T T-T, Baltussen R, Adam T, Torres TT, Hutubessy Acharya RA, Evans DB, et al., editors. Making choices in health: WHO guide to cost-effectiveness analysis. Geneva: World Health Organization, 2003. 312 p.

24. Registrar General of India. Census of India. New Delhi: Registrar General of India, 2001. (http://www. censusindia.net, accessed on 1 March 2008).

25. Whittington D, Sur D, Cook J, Chatterjee S, Maskery B, Lahiri $\mathrm{M}$ et al. Rethinking cholera and typhoid vaccination policies for the poor: private demand in Kolkata, India. World Dev 2009;37:399-409.

26. Naficy A, Rao MR, Paquet C, Antona D, Sorkin A, Clemens JD. Treatment and vaccination strategies to control cholera in sub-Saharan refugee settings: a cost-effectiveness analysis. JAMA 1998;279:521-5.

27. Cookson ST, Stamboulian D, Demonte J, Quero L, Martinez de Arquiza C, Aleman A et al. A cost-benefit analysis of programmatic use of CVD 103-HgR live oral cholera vaccine in a high-risk population. Int J Epidemiol 1997;26:212-9.

28. United Nations Educational, Scientific and Cultural Organization. Statistics on primary and secondary net enrollment. Quebec: UNESCO Institute for Statistics, 2008. (http://stats.uis.unesco.org, accessed on 1 October 2008).

29. Mathers CD, Vos T, Lopez AD, Salomon J, Ezzati M. National burden of disease studies: a practical guide. 2.0 ed. Geneva: Global Programme on Evidence for Health Policy, World Health Organization, 2001. 137 p.

30. Bhattacharya S, Alberini A, Cropper ML. The value of mortality risk reductions in Delhi, India. J Risk Uncertainty 2007;34:21-47.
31. World Bank. World development report 1993: investing in health. New York, NY: Oxford University Press, 1993. 344 p.

32. Jamison DT, Breman JG, Measham AR, Alleyne G, Claeson M, Evans DB et al., editors. Disease control priorities in developing countries. 2nd ed. New York, NY: Oxford University Press, 2006. 1,400 p.

33. Laxminarayan R, Mills AJ, Breman JG, Measham AR, Alleyne G, Claeson M et al. Advancement of global health: key messages from the Diseases Control Priorities Project. Lancet 2006;367:1193-208.

34. World Health Organization. World health statistics 2007. Geneva: World Health Organization, 2007. 80 p. (http://www.who.int/whosis/en/, accessed on 1 December 2007).

35. India. Ministry of Health and Family Welfare. National Health Accounts Cell. National health accounts, India, 2001-2002. New Delhi: IG Printers Pvt. Ltd., 2005. 79 p. (http://www.mohfw.nic.in/NHA\%20 2001-02.pdf, accessed on 1 March 2008).

36. Deolalikar AB, Jamison DT, Jha P, Laxminarayan R. Financing health improvements in India. Health Aff 2008;27:978-90.

37. van Doorslaer E, O'Donnell O, Rannan-Eliya RP, Somanathan A, Adhikari SR, Garg CC et al. Catastrophic payments for health care in Asia. Health Econ 2007; 16:1159-84.

38. Lauria DT, Maskery B, Poulos C, Whittington D. An optimization model for reducing typhoid cases in developing countries without increasing public spending. Vaccine 2009;27:1609-21. 